\title{
CONFIGURACIÓN DE LA IMAGEN DE MARÍA MAGDALENA EN LA ANTIGÜEDAD Y EDAD MEDIA
}

\section{CONFIGURATION OF THE IMAGE OF MARIA MAGDALENA IN ANTIQUITY AND THE MIDDLE AGES}

\author{
Julio Morales Folguera \\ (Universidad de Málaga, España) \\ juliomorales.53@hotmail.com
}

Recibido: 02 abril 2020 Aceptado: 20 mayo 2020 Publicado: 01 julio 2020

Resumen: A lo largo de este artículo nos proponemos acercarnos a la figura de María Magdalena a través de las distintas fuentes literarias y su repercusión en la iconografía. Discípula de Jesús, testigo de su enseñanza y de su vida, fue la primera persona que tuvo noticia de su resurrección y que la comunicó a los discípulos. Esta mujer ha sido objeto de admiración, pero también de controversias a lo largo de los siglos. Su nombre no está vinculado a un varón, no lleva el apellido de su padre o de su esposo, sino el de la ciudad de Magdala. Lleva por sobrenombre un topónimo, que es el de su lugar de origen, en la orilla noroccidental del Lago de Tiberíades de la región de Galilea, desde donde había seguido a Jesús. La historia de la cristiandad la convirtió en uno de los personajes más populares, siendo fuente de inspiración para numerosos pintores y escultores; y sobre su persona se han elaborado leyendas, fábulas, poesías, novelas, obras de teatro y ensayos. Se puede decir que cada época ha creado a su Magdalena en función de sus necesidades e intereses. A la figura originaria de la Magdalena como seguidora de Cristo, se han añadido ideas y leyendas que llegaron a configurar su imagen mítica. Las imágenes cambian, pero son importantes para expresar conceptos y así ha ocurrido con las distintas imágenes sobre María Magdalena a lo largo de la Antigüedad, Edad Media y épocas posteriores.

Palabras clave: María Magdalena, Evangelios canónicos, Evangelios gnósticos, Apostolorum apostol, teoría de la unidad.

Abstract: Throughout this article we propose to approach the figure of María Magdalena through the different literary sources and their impact on the iconography. She, disciple 
of Jesus, witness of his teaching and of his life, was the first person who had the news of his resurrection and the communication to the disciples. This woman has been the object of admiration, but also of controversy throughout the centuries. Her name is not limited to a male, it does not bear the surname of her father or her husband, but that of the city of Magdala. It is nicknamed a place-name, which is the place of origin, on the north-western shore of Lake Tiberias in the Galilee region, from where he had followed Jesus. The history of Christianity changed her into one of the most popular characters, being a source of inspiration for numerous painters and sculptors; legends, fables, poetry, novels, plays, and essays have been made about her. It can be said that each age has created its Magdalena according to its needs and interests. Ideas and legends have been added to the original figure of Magdalena as a follower of Christ that came to shape her mythical image. The images change, but they are important to identify concepts and this has happened with the different images of Mary Magdalene throughout Antiquity, the Middle Ages and following times.

Keywords: Maria Magdalena, Canonical gospels, Gnostic gospels, Apostolorum apostola, unity theory.

\section{Introducción}

Sobre María Magdalena se han escrito páginas con enfoques diversos, y muchos autores han desfigurado la verdadera imagen de la Magdalena a lo largo de la Historia en beneficio de sus opiniones y creencias personales, sin ningún tipo de fundamento histórico, religioso y científico (Amo Horga, 2008, p. 614). Las fuentes más antiguas escritas sobre ella, donde nos encontramos pocos datos acerca de esta mujer y que datan del siglo I, son los Evangelios canónicos (Mateo, Marcos, Lucas y Juan). En los Evangelios gnósticos se pueden observar muchos rasgos que aparecerán en la imagen contemporánea de la Magdalena. A partir del siglo VI fue el papa Gregorio Magno quien construyó definitivamente su identidad durante un milenio, estableciendo que la pecadora de Lucas, María de Betania y María Magdalena eran la misma persona (teoría de la unidad). La leyenda posterior la hizo pasar el resto de su vida en una cueva en el desierto, haciendo penitencia y mortificando su carne, siendo frecuentes en el arte occidental las representaciones de la Magdalena penitente. Y así, dejó su papel de testigo privilegiado de la resurrección y pasó a ser ejemplo de la mujer pecadora y arrepentida (Rocco, 2007, p. 175). Hoy 
esta mujer continúa vigente en el cine, en la literatura, en la música. Se ha puesto de moda tras el éxito de la novela, entre otras, de Dan Brown El Código Da Vinci (2003).

\section{María Magdalena en los Evangelios Canónicos}

Las fuentes más antiguas escritas sobre María Magdalena son los Evangelios canónicos, es decir, los Evangelios de Mateo, Marcos, Lucas y Juan, que pertenecen al Nuevo Testamento y datan del siglo I. Estos Evangelios se pueden considerar como la única fuente auténtica, al ser la más antigua sobre ella (Amo Horga, 2008, p. 614615).

María Magdalena es mencionada en los Evangelios canónicos como una distinguida discípula de Jesús, siendo nombrada en primer lugar entre las mujeres que siguen a Jesús, porque en los Evangelios el orden en el cual se nombran a los personajes no suele ser casual (Amo Horga, 2008, p. 615).

La información sobre María Magdalena en los Evangelios canónicos es escasa. Y así, aparece citada sólo en doce pasajes relacionados con el seguimiento, la crucifixión y la resurrección de Jesús. En primer lugar, formando parte de las mujeres seguidoras de Jesús, que pertenecían al grupo de sus primeros discípulos. Lucas (Lc 8, 1-3) recoge los nombres de María, llamada Magdalena, de la que había echado siete demonios; Juana, mujer de Cusa, administrador de Herodes; y Susana, de la que no tenemos ninguna otra referencia en el Evangelio, que junto a otras mujeres curadas por Jesús, la sanación se transformaría en seguimiento (Amo Horga, 2008, p. 615). No sabemos nada de María Magdalena desde el momento en que es curada por Jesús hasta el momento de la crucifixión. Algunos autores suponen que siguió a Jesús con los Apóstoles y otras mujeres (Amo Horga, 2008, p. 616). En segundo lugar, contemplando la Crucifixión junto a la madre de Jesús, María de Cleofás y Salomé (Lc 23, 49; Mc 15, 40-41; Mt 27, 55-56; Jn 19, 25). Y en tercer lugar, en el sepulcro junto a María la de Santiago, Juana y Salomé para embalsamar el cuerpo de Jesús, y en las apariciones del Resucitado (Lc 24, 1-10; Mc $16,1-8$ y 16-9; Mt 27, 61 y 28, 1-10; Jn 20, 1-10 y 11-19).

\section{María Magdalena en los Evangelios Gnósticos}

Existen otros textos, además de los Evangelios canónicos, en los que aparece María Magdalena. Estos quedaron fuera del canon, por lo que se denominaron extracanónicos 
$o$ apócrifos. Entre ellos se encuentran los Evangelios gnósticos1, donde se pueden encontrar muchos rasgos que serán relevantes para la formación de la iconografía contemporánea sobre la Magdalena (Amo Horga, 2008, p. 621). Entre los apócrifos gnósticos se presta singular atención a los manuscritos hallados en la Biblioteca de NagHammadi entre 1945 y 1946, en el Alto Egipto2. Estos textos son el Evangelio de Felipe, el Evangelio de Tomás, el Diálogo del Salvador y la Sabiduría de Jesucristo. El contenido de estos textos permitió ampliar el conocimiento de las doctrinas gnósticas (Amo Horga, 2008, p. 622). Por otro lado, hay que citar también otras obras como el Evangelio de María y Pistis Sophia, que se conocían antes de los descubrimientos de Nag-Hammadi, pero que se suelen citar junto a ellos por su carácter gnóstico (Bernabé Ubieta, 2018, p. 213).

Hasta la aparición en 1945 de estos manuscritos, lo que se sabía de María Magdalena era lo que dicen los Evangelios canónicos. Los textos de Nag-Hammadi, la mayoría de ellos esotéricos, en los que María Magdalena aparece mencionada en más ocasiones que en los textos canónicos, nos presentan una imagen de ella muy diferente a la que se encuentra en los Evangelios canónicos (Mar Marcos \& Juana Torres, 2007, p. 135-136). María Magdalena, llamada normalmente Miriam, asume en los textos gnósticos un papel muy relevante junto con los otros discípulos como receptora y transmisora de las enseñanzas secretas de Jesús, que los gnósticos, depositarios de ellas, consideraban como verdaderas (Mar Marcos \& Juana Torres, 2007, p. 136). Estos textos otorgan a María Magdalena un puesto más importante que el que le dan los Evangelios canónicos. María aparece como la intérprete más capacitada entre los discípulos y oponiéndose violentamente a Pedro, debido a la participación de las mujeres en el culto. La mujer de Magdala representa un cristianismo más abierto a las mujeres y, por tanto, más liberal (Burnet, 2007, p. 65).

En el Evangelio de Tomás, una colección de logias o dichos, llamado el quinto evangelio y muy valorado por los gnósticos cristianos de la Antigüedad, en el

\footnotetext{
${ }^{1}$ Con el término gnosticismo se denominan diferentes corrientes religiosas cristianas que se caracterizaban por una creencia común en la gnosis, término que en griego significa conocimiento o sabiduría. Para los gnósticos, grupo minoritario y elitista, que floreció en los siglos II y III, la gnosis era un tipo de conocimiento particular, el único conocimiento único, conocimiento verdadero obtenido directamente de Dios que permitía alcanzar la salvación (Amo Horga, 2008, p. 621-622).

${ }^{2}$ La Biblioteca de Nag-Hammadi está formada por manuscritos coptos del siglo IV, que son copias de manuscritos escritos originalmente en griego. La más temprana fecha de composición de estos documentos es de la mitad del siglo II, algunos incluso de fines del siglo I, contemporáneos de los Evangelios canónicos del Nuevo Testamento.
} 
logion 21 (Santos Otero, 1999, p. 693) aparece María interviniendo en una asamblea en la que hombres y mujeres poseen las mismas prerrogativas, constituyendo una diferencia respecto a los Evangelios canónicos (Burnet, 2007, p. 66). Y en el logion 114 (Santos Otero, 1999, p. 705), podemos ver cómo María se enfrentó a la misoginia de Pedro apóstol: Que se aleje Mariham de nosotros, pues las mujeres no son dignas de la vida.

En el Evangelio de Felipe se habla de María Magdalena como compañera de Jesús, en una relación tan cercana como la de los apóstoles, caminando continuamente con el Señor junto a su madre María y la hermana de ésta (Santos Otero, 1999, p. 722).

El Diálogo del Salvador es un diálogo de Jesús con tres de sus discípulos: Judas, Mateo y María, quienes han recibido una visión y, a través de ella, un mayor conocimiento (Bernabé Ubieta, 2018, p. 211). Aunque María Magdalena aparece como uno más de los discípulos, se reconoce en ella el carácter de la discípula perfecta, la mujer que ha comprendido completamente (Mar Marcos \& Juana Torres, 2007, p. 141).

La Sabiduría de Jesucristo es un diálogo de revelación típicamente gnóstico, en el que se desprecia la sabiduría de los filósofos a cambio de la del Cristo resucitado (Mar Marcos \& Juana Torres, 2007, p. 142). María representa a las mujeres, a las que les será reservado un puesto importante (Burnet, 2007, p. 66).

El Evangelio de María es una de las mejores pruebas de la autoridad de la que gozaba María Magdalena entre los gnósticos. En el texto, María reconforta y anima a los discípulos a la predicación, y Pedro reconoce entonces el lugar privilegiado de María junto al Salvador y su magisterio (Mar Marcos \& Juana Torres, 2007, p. 143). Ella ha recibido una revelación secreta y es presentada con una autoridad superior a la de Pedro, emanada de su cualidad de primera testigo de la resurrección (Bernabé Ubieta, 2018, p. 215-216).

María Magdalena alcanza un papel muy relevante en Pistis Sophia, un diálogo entre Jesús y sus discípulos. En el texto María es alabada por su gran capacidad para comprender los misterios que Jesús les revela (Mar Marcos \& Juana Torres, 2007, p. 147). Entre todos los discípulos de Jesús, ella es en verdad la más próxima a Él (Burnet, 2007, p. 67).

Finalmente, habría que citar el Evangelio apócrifo de Pedro, que sólo menciona a María Magdalena en las logias 50-57 junto a otras mujeres, en su papel de testigo de la resurrección de Jesús (Santos Otero, 1999, p. 385-387). 


\section{María Magdalena en la Iglesia Occidental y en la Iglesia Oriental}

Desde fechas muy tempranas, la tradición cristiana de Occidente fundió en la persona de María Magdalena las tres mujeres distintas que seguían a Jesús en los Evangelios: la pecadora de Lucas (Lc 7, 36-50), María Magdalena (Lc 8, 2) y María de Betania (Jn 12, $1-11)$.

Fueron los Padres de la Iglesia Occidental (San Jerónimo, San Ambrosio, San Agustín y San Gregorio Magno) los que empezaron a hablar de una única Magdalena, por no encontrar en las Sagradas Escrituras razón de peso para decir que fueran tres personas distintas. Esta posición fue mantenida también, entre otros, por San Isidoro de Sevilla, Santo Tomás de Aquino y San Buenaventura (La Puerta Montoya, 2005, p. 964).

Pero fue el papa Gregorio Magno (540-604) quien construyó definitivamente la identidad y las funciones que conservará esta mujer durante casi un milenio (la misma mujer, y ejemplo de penitencia y arrepentimiento para los fieles) en dos homilías que pronunció. La primera sobre el Noli me tangere (Jn 20, 11-18), y la segunda sobre la unción de la pecadora (Lc 7, 36-50). Y así afirma: Esta mujer que Lucas llama la pecadora y Juan María, nosotros creemos que es esa María de la que Marcos afirma que de ella fueron arrojados siete demonios (Burnet, 2007, p. 43-44).

Por consiguiente, a partir del siglo VI San Gregorio Magno estableció que la pecadora de Lucas, María de Betania y María Magdalena eran la misma persona, conociéndose esta afirmación como teoría de la unidad (Roselló Soberón, 2009, p. 64).

Una de las razones por las que se identifica a María Magdalena con la mujer pecadora es que Lucas antes de hablar de los siete demonios de María de Magdala $(\mathrm{Lc} 8,2)$, narra el relato del perdón de la mujer pecadora en casa de Simón el fariseo (Lc $7,37)$, estableciendo una relación entre ambas. Debido a la proximidad textual, se trataría, pues, de la misma persona (Roselló Soberón, 2009, p. 64).

Al identificarla el papa Gregorio Magno con la pecadora de Lucas, la leyenda posterior la hizo pasar el resto de su vida en una cueva en el desierto, haciendo penitencia y mortificando su carne, siendo frecuentes en el arte occidental las representaciones de la Magdalena penitente. También María Egipcíaca, santa del siglo V, se retiró al desierto a expiar sus culpas (Vorágine, 1982, p. 238), influyendo de alguna 
manera en la creación de la María Magdalena penitente posterior. Y así dejó su lugar de discípula y de líder, que abandonara su papel de testigo privilegiado de la resurrección, que no se la reconociera en su papel de intermediaria entre el Maestro y su primera comunidad; y que pasara a ser la mujer pecadora, la que se arrepiente y cuyo destino sería un modelo a seguir de cambio de vida (Rocco, 2007, p. 175).

La Iglesia Oriental, por el contrario, siguió los criterios de Orígenes (184-253), para quien nos encontramos ante tres mujeres distintas, optando por celebrar tres santas con festividades distintas (García Álvarez, 2018, p. 58). María de Magdala procedía de una ciudad de Galilea, mientras que María de Betania era originaria de Judea, junto a Jerusalén. Por consiguiente, la distancia entre ambas ciudades sería una prueba de que se trataría de dos mujeres distintas (Burnet, 2007, p. 49). Además, la razón fundamental por la cual se trataría de tres personas diferentes reside en que ninguno de los Evangelios menciona el nombre de la Magdalena en el episodio de la pecadora en casa del fariseo, ni cuando se refieren a María la hermana de Lázaro y de Marta.

En la tradición medieval de Occidente continuó la identificación de estas tres mujeres con María Magdalena. Sin embargo, esta unificación comenzó a ser rechazada en el siglo XVI, siendo el primero en disociar las tres personas el dominico y humanista francés Jacques Lefévre d'Étaples (Delenda, 2019, p. 277), quien en 1516 publicó su disertación De María Magdalena, en la que sostiene que la pecadora de Lucas, la hermana de Marta y María Magdalena son tres personajes evangélicos distintos; pero Francia era el centro que promocionaba el culto de la Magdalena y texto de Lefévre fue condenado por la Sorbona (Amo Horga, 2008, p. 629). No obstante, la tradición se mantuvo y se volvió a reunir a las tres mujeres en la figura de Santa María Magdalena.

Hoy en día la Iglesia Católica se ha pronunciado por la distinción entre las tres mujeres rechazando la teoría unitaria, ateniéndose sólo a los datos de los Evangelios canónicos. Fue el papa Pablo VI el que, en 1969, retiró del Calendario litúrgico el adjetivo de penitente adjudicado a María Magdalena, rasgo más conocido de ella y el que menos la identificaría como tal. En 1998 el papa Juan Pablo II, en su Carta apostólica Mulieris Dignitatem3, afirmó que María Magdalena había sido llamada apostolorum apostola, la

\footnotetext{
${ }^{3}$ Una Carta apostólica es un tipo de documento oficial elaborado por el Pontífice de la Iglesia Católica, en forma de carta y dirigida a una persona determinada o a un grupo, aunque su intención es normalmente universal (Pedro, A. de,
} 
apóstol de los apóstoles, haciendo hincapié en que antes que los apóstoles, fue testigo ocular de Cristo resucitado y fue también la primera en dar testimonio de él ante los apóstoles. Finalmente, el 10 de junio de 2016, la Congregación para el Culto Divino y la Disciplina de los Sacramentos publicó un decreto por el cual se elevaba la memoria de santa María Magdalena, hasta ahora memoria obligatoria4, al grado de fiesta en el Calendario Romano General, por expreso deseo del papa Francisco. Era justo que la celebración litúrgica de esta mujer tuviera el mismo grado de festividad que se da a la celebración de los apóstoles, resaltando la misión especial de María Magdalena.

\section{Incidencias en los tipos iconográficos de maría Magdalena}

Después de Jesús y la Virgen María, María Magdalena es uno de los personajes de la Biblia más representados a lo largo de la historia. En España supera las imágenes de Santiago, Santa Teresa de Jesús o de San Sebastián (Sánchez Morillas, 2014, p. 93).

Las características y los atributos de María Magdalena permiten reconocerla fácilmente, aunque a veces se la ha confundido con María Egipcíaca, con quien tiene en común algunos de sus rasgos, como el atributo de la larga cabellera suelta (Réau L., 2001, p. 297).

Es importante subrayar la distinción existente entre la iconografía de María Magdalena en Occidente, donde llega a ser una penitente sin ropaje alguno, a la de Oriente donde no pierde su castidad (Sánchez Morillas, 2014, p. 83). En el arte oriental María Magdalena no tendrá un protagonismo como en el arte occidental, y será representada formando parte del grupo de mujeres en los episodios de la Crucifixión, Descendimiento y la Resurrección (Sánchez Morillas, 2014, p. 87). La imagen de la Magdalena en Oriente ha seguido las representaciones de ella en los Evangelios canónicos; mientras que en Occidente su figura ha experimentado una serie de cambios, en gran parte por la teoría unitaria y las leyendas, apareciendo las imágenes de la Magdalena como pecadora o como una de las mujeres de las unciones a Cristo, a las que se le añadían las escenas del ciclo de Marsella (Sánchez Morillas, 2014, p. 88).

1990, p. 35). Mulieris Dignitatem es una Carta apostólica del Sumo Pontífice Juan Pablo II sobre la dignidad y la vocación de la mujer con ocasión del año mariano, el 15 de agosto de 1988.

${ }^{4}$ Se considera memoria la celebración litúrgica de grado inferior al de solemnidad, fiesta y domingo (Pedro, A. de, 1990, p. 154). 
En el siglo XIII podemos encontrar a María Magdalena desnuda, pero revestida completamente por los cabellos, en una identificación con María Egipcíaca en un fresco de la iglesia de San Próspero en Perugia (Italia), imagen que evidencia el período eremítico de la santa de la leyenda provenzal (Sánchez Morillas, 2014, p. 90). Sin embargo, será en la Italia de comienzos del siglo XVI cuando se muestre su desnudo como una Venus espiritualizada, una diosa del amor, como se puede apreciar en algunas obras de Tiziano, Correggio, Giampietrino o Ippolito Borghese, entre otros muchos (Sánchez Morillas, 2014, p. 90).

La llegada de la Contrarreforma ocasionará un cambio en la iconografía de María Magdalena. Así, en la asamblea conciliar no 245 del Concilio de Trento (1545-1563), se establecerán normas básicas de representación para acabar con ciertas exageraciones. Se insistirá en el enfoque iconográfico de los Evangelios canónicos (Sánchez Morillas, 2014, p. 91). Como consecuencia, una de las modificaciones con respecto a la Magdalena va a ser no presentarla demasiado arreglada, produciéndose contrastes rotundos entre la Magdalena previa a la Contrarreforma, como la de Jan van Scorel, ataviada con perlas y ropajes ornamentales, y la Magdalena de Murillo, tapada con telas sin costuras ni detalles. También señaló el Concilio que los santos no debían mostrar las piernas, norma de la que procedería la representación de las Magdalenas de medio cuerpo (Sánchez Morillas, 2014, p. 91). De todas estas normas se hará una excepción con su representación como penitente en su retiro en la cueva, debido a su ejemplo para la meditación. Y así la veremos con la calavera, el crucifijo y otros símbolos, reflexionando sobre la fugacidad de la vida, la muerte y la redención. Por consiguiente, corresponderá a la segunda mitad del siglo XVI la iconografía de María Magdalena como penitente (Sánchez Morillas, 2014, p. 91). Sin embargo, el desnudo parece escapar a la indicación de Trento a vestir las imágenes con decoro, y esta Magdalena penitente nos presentará una mujer menos casta que la anterior a la Contrarreforma, llegando su apogeo en el siglo XVII, con representaciones de la santa en éxtasis místico, con los ojos vueltos al cielo (Sánchez Morillas, 2014, p. 91).

En cuanto a las representaciones aisladas de la Magdalena, se pueden reducir a dos tipos: la de la unción, que tiene como atributo un vaso de perfumes y es la imagen 
preferida por el arte de la Edad Media; y la de la Magdalena arrepentida, que tiene como atributo una calavera o la corona de espinas y es la elegida por el arte barroco de la Contrarreforma (Réau, L., 2001, p. 297) [1]

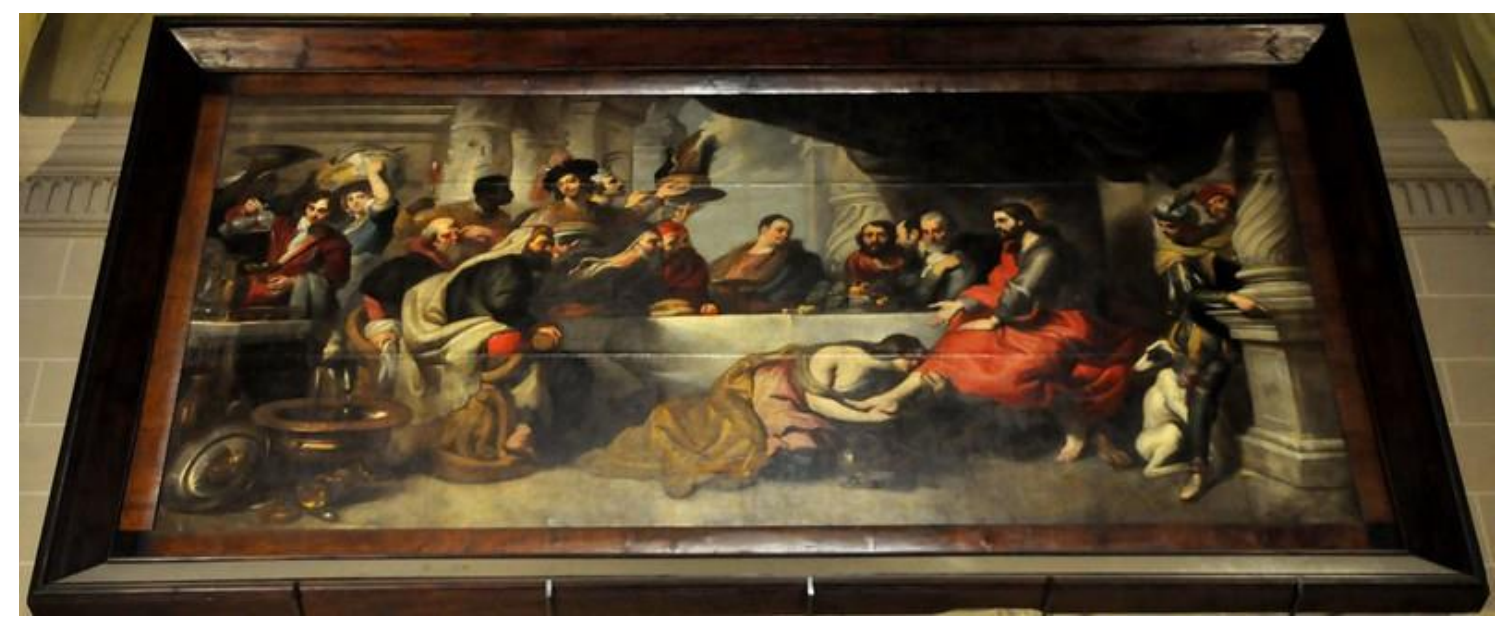

1. El convite de Jesús en casa de Simón el Fariseo. Miguel Manrique (1642), Catedral de Málaga.

El lienzo plasma la escena narrada por Lc 7, 37-39. Una mujer pecadora, que no debe confundirse ni con María de Betania ni con María Magdalena, bañó los pies de Jesús con sus lágrimas, los enjugó con sus cabellos, los besó y los ungió con un perfume que llevaba en un vaso de alabastro.

\section{Conclusiones}

Como hemos visto, este personaje ha tenido una larga y compleja historia. Su figura es interpretada de forma diferente según el cristianismo oriental y el occidental. Es la primera que ve a Cristo resucitado y es encargada de comunicarlo a los Apóstoles; de este modo, al tener su testimonio poco valor en esa época por ser mujer, se convierte en una historia verdadera. Históricamente, por los Evangelios canónicos, no se puede identificar a María Magdalena con María de Betania y con la mujer pecadora de Lucas, no llegando a afectar al arte la polémica entre una única protagonista o tres distintas. Así mismo, en Oriente la iconografía de la Magdalena sigue las representaciones que de ella encontramos en los Evangelios canónicos; mientras que en Occidente, debido a las influencias de la teoría unitaria y de las leyendas medievales, especialmente de la Leyenda dorada, aparecen con frecuencia las imágenes de la Magdalena ungiendo a Cristo, que es la más frecuente en el arte medieval, y la penitente, que es la preferida por el arte barroco, 
como así representaron pintores como El Greco, José Ribera o Pedro de Mena, para los que la Magdalena era la mujer que renunciaba a las vanidades del mundo para conseguir la salvación.

\section{Referencias bibliográficas}

Amo Horga, Luz María del (2008), María Magdalena, la Apóstola apostolorum, El culto a los santos: cofradías, devoción, fiestas y arte, Ediciones Escurialenses: Real Centro Universitario Escorial-María Cristina. Madrid: p. 613-636.

Bernabé Ubieta, Carmen (2018), María Magdalena. Tradiciones en el Cristianismo primitivo. Ed. Verbo Divino: Estella (Navarra).

Burnet, Régis (2007), María Magdalena. Siglo I al XXI. De pecadora arrepentida a esposa de Jesús. Desclée de Brouwer: Bilbao.

Delenda, Odile (2019), La Magdalena en el Arte. Un argumento de la Contrarreforma en la Pintura española y mejicana del siglo XVII. En Actas del IIIer Congreso del Barroco Iberoamericano, Tomo I. Sevilla, p. 277-289.

García Álvarez, César (2018), La imagen de María Magdalena en la literatura del Siglo de Oro español. Revista agustiniana, vol. 59, nº 178-179, p. 55-108.

La Puerta Montoya, Magdalena de (2005), La figura de la Magdalena en la Pintura Española del Siglo de Oro. En Mata Induráin, Carlos (dir). En Actas del Congreso El Siglo de Oro en el Nuevo Milenio. Pamplona, Eúnsa, p. 963-978.

Mar Marcos \& Juana Torres (2007), El evangelio de María Magdalena y la literatura gnóstica. En Gómez-Acebo, Isabel (dir), María Magdalena. De apóstol, a prostituta y amante. Bilbao, Desclée de Brouwer, p. 117-151.

Pedro, Aquilino de (1990), Diccionario de términos religiosos y afines. Editorial Verbo Divino, Estella (Navarra).

Réau, L. (2001): Iconografía de los santos G-O. En Iconografía del arte cristiano, tomo 2/vol. 4. Ed. del Serbal, Barcelona, p. 293-306.

Rocco, Diana (2007), María Magdalena en la patrística. En Gómez-Acebo, Isabel (dir), María Magdalena. De apóstol, a prostituta y amante. Bilbao, Desclée de Brouwer, p. 153-176. 
Roselló Soberón, Estela (2009), El cuerpo de María Magdalena en un devocionario novohispano: La corporalidad femenina en la Historia de la Salvación del siglo XVIII. En Corporalidad femenina y Salvación. Instituto de Investigaciones Históricas. Universidad Nacional Autónoma de México, p.57-79.

Sánchez Morillas, Beatriz (2014), María Magdalena, de testigo presencial a icono de penitencia en la pintura de los siglos XIV-XVII. Tesis doctoral, Universidad de Sevilla.

Santos Otero, Aurelio de (1999), Los Evangelios Apócrifos. B.A.C.: Madrid.

Schökel, Luis Alonso \& MATEOS, Juan (1977), Nueva Biblia Española. Ediciones Cristiandad: Madrid.

Vorágine, Santiago de la (1982). La leyenda dorada, trad. J.M. Macías. Alianza: Madrid. 